\title{
Striatal hypoactivation and cognitive slowing in patients with partially remitted and remitted major depression
}

DOI:

10.1002/pchj.134

\section{Document Version}

Accepted author manuscript

Link to publication record in Manchester Research Explorer

\section{Citation for published version (APA):}

Hammar, A., Neto, E., Clemo, L., Hjetland, G. J., Hugdahl, K., \& Elliott, R. (2016). Striatal hypoactivation and cognitive slowing in patients with partially remitted and remitted major depression. Psych Journal.

https://doi.org/10.1002/pchj.134

\section{Published in:}

Psych Journal

\section{Citing this paper}

Please note that where the full-text provided on Manchester Research Explorer is the Author Accepted Manuscript or Proof version this may differ from the final Published version. If citing, it is advised that you check and use the publisher's definitive version.

\section{General rights}

Copyright and moral rights for the publications made accessible in the Research Explorer are retained by the authors and/or other copyright owners and it is a condition of accessing publications that users recognise and abide by the legal requirements associated with these rights.

\section{Takedown policy}

If you believe that this document breaches copyright please refer to the University of Manchester's Takedown Procedures [http://man.ac.uk/04Y6Bo] or contact uml.scholarlycommunications@manchester.ac.uk providing relevant details, so we can investigate your claim.

\section{OPEN ACCESS}




\begin{abstract}
The present pilot study investigated neuronal correlates of executive functioning in patients previously diagnosed with recurrent Major Depressive Disorder (MDD). The aim of the study was to examine a partial remitted and remitted MDD patient group with functional magnetic resonance imaging (fMRI) using a cognitive activation paradigm in order to probe aspects of response inhibition, attention shift and working memory. Twenty MDD patients and 19 healthy controls, matched for age and gender, participated in the study. A working memory n-back task with single presentations of incongruent Stroop words was used, with the instruction to either remember the colour of the ink the word was written in, or the colour word itself, presented 2 or 3 words back in the presentation series. MR images were acquired on a 1.5T GE Signa HD MR scanner. In addition to MR data, response time (RT) and response accuracy (RA) behavioural data were recorded. The behavioural results showed longer RT and lower RA in the MDD group compared to the control group across instruction conditions and working memory load. Based on previous studies of executive function, a composite ROI mask of the anterior cingulate cortex (ACC), dorsolateral prefrontal cortex (DLPFC), caudate and putamen was used in statistical analysis. Significant activation was observed in controls throughout this corticostriatal network. When compared to controls, patients showed no significant difference in the level of activation in the ACC and the DLPFC. However, in the putamen and caudate, hypoactivation in the patient group was observed. It was concluded that these effects could be due to a scar effect as a result of previous episodes of MDD.
\end{abstract}

Keywords: fMRI; Striatal; Hypoactivation; Cognitive slowing; Partial remitted depression; Cognitive functioning 


\section{Introduction}

It is generally acknowledged that Major Depressive Disorder (MDD) is associated with cognitive impairment, particularly impairment of attention and executive function (E Bora, Harrison, Yücel, \& Pantelis, 2013; Castaneda, Tuulio-Henriksson, Marttunen, Suvisaari, \& Lönnqvist, 2008; Hammar \& Årdal, 2009; Rock, Roiser, Riedel, \& Blackwell, 2014; Snyder, 2013). In addition, recent research focuses on persistent cognitive impairment in MDD. Several studies indicate that cognitive impairments persist despite of a reduction in clinical symptoms (Airaksinen, Wahlin, Larsson, \& Forsell, 2006; Hammar, Lund, \& Hugdahl, 2003; Hammar \& Schmid, 2013; Hammar et al., 2010; Hammar \& Årdal, 2013; Schmid, Strand, Årdal, Lund, \& Hammar, 2011; Årdal \& Hammar, 2011) and are even observed in patients in full remission (Gruber, Rathgeber, Bräunig, \& Gauggel, 2007; Majer et al., 2004; Nakano et al., 2008; Neu et al., 2005; Paelecke-Habermann, Pohl, \& Leplow, 2005; Reischies \& Neu, 2000; Smith, Muir, \& Blackwood, 2006; Weiland-Fiedler et al., 2004; Wekking, Bockting, Koeter, \& Schene, 2012; Årdal \& Hammar, 2011). However, other studies have reported recovery of cognitive functioning in remission (Biringer et al., 2005; Hammar \& Schmid, 2013; Hammar \& Årdal, 2012; Koetsier et al., 2002; Lahr, Beblo, \& Hartje, 2007). Recent meta-analyses point to persisting executive impairment despite remission (E Bora et al., 2013; Hasselbalch, Knorr, \& Kessing, 2011; Rock et al., 2014). There is however an inconsistency across studies regarding persistent cognitive impairment. It has been suggested that this is explained by different subgroups of MDD patients which show different neurocognitive profiles (E Bora et al., 2013).

There is also inconsistency regarding the brain mechanisms of the cognitive impairments seen in MDD. Many studies have reported altered brain activation in MDD associated with performance of cognitive tasks, including executive tasks, which are thought to especially rely on prefrontal cortical regions (see overview: (Diener et al., 2012; Elliot \& 
Dolan, 2002; Thomas \& Elliott, 2009). However, the directions of activation alteration vary across studies, resulting in two contrasting models being proposed.

The first model is based on studies that have reported decreased frontal activation during cognitive tasks, with significantly poorer behavioural performance (Hugdahl et al., 2004; Okada, Okamoto, Morinobu, Yamawaki, \& Yokota, 2003; Rodríguez-Cano et al., 2014). This pattern of brain activation has been described as hypo-responding (Thomas \& Elliott, 2009). The second model has emerged from another set of studies showing increased prefrontal activity during cognitive tasks, accompanied by normal cognitive performance (Fitzgerald et al., 2008; Harvey et al., 2005; Langenecker et al., 2007; Wagner et al., 2006; Walter, Wolf, Spitzer, \& Vasic, 2007). These results have been suggested to be caused by 'cortical inefficiency' (Harvey et al., 2005) and explained as hyper-responding (Thomas \& Elliott, 2009).

However, these hypoactivation and hyperactivation patterns displayed by MDD patients are not always seen in studies. Siegle, Thompson, Carter, Steinhauser, and Thase (Siegle, Thompson, Carter, Steinhauer, \& Thase, 2007) reported decreased dorsolateral prefrontal cortex (DLPFC) activity, but accompanied by normal performance on an executive task. Similarly, Gyurak et al. (Gyurak et al., 2015) found hypoactivation in DLPFC during response inhibition together with normal performance, specifically in patients who did not respond to subsequent antidepressant treatment. In a review by Rogers and colleagues (Rogers et al., 2004), no significant difference in DLPFC activation between depressed and non-depressed samples was reported. Elliott and colleagues (R Elliott et al., 1997) also showed normal activity of the DLPFC accompanied by impaired performance on a planning task. Instead, they found hypoactivation of caudate nucleus of the striatum. Altered striatal activity was also found in a study by Aizenstein and colleagues (Aizenstein et al., 2005). They found increased striatal activity together with hypoactivation DLPFC and normal performance in explicit learning in older depressed patients. Activation in the striatum during executive task performance in depression has rarely been 
investigated, despite the striatum's role in networks associated with cognition (J. P. Hamilton et al., 2012). The striatum has been linked to frontal cortex both structurally and functionally and is the primary input region for frontostriatal, corticostriatal or cortico-striatal-pallidal-thalamic circuits (Marchand \& Yurgelun- Todd, 2010). Corticostriatal circuits have been proposed as critical substrates of cognition with extensive connections to other brain regions (Marchand \& Yurgelun- Todd, 2010; Tekin \& Cummings, 2002). Cognitive impairments in neuropsychiatric disorders, including MDD, may therefore be consistent with corticostriatal dysfunction (Chudasama \& Robbins, 2006; Drevets, 2000; Rebecca Elliott, 2003; Furman, Hamilton, \& Gotlib, 2011; J. P. Hamilton et al., 2012; Marchand \& Yurgelun- Todd, 2010; Mayberg et al., 1999; Tekin \& Cummings, 2002).

Most imaging studies of MDD have focused on patients in a current depressive state. The neuronal underpinnings of persisting cognitive impairments in remitted MDD patients have only been addressed in a few previous studies (Bartova et al., 2015; Gyurak et al., 2015; Hugdahl et al., 2007; Takami, Okamoto, Yamashita, Okada, \& Yamawaki, 2007). Hugdahl and colleagues (Hugdahl et al., 2007) performed a two-year follow-up on remitted patients diagnosed with recurrent MDD. They found significantly increased parietal and frontal activation during a mental arithmetic task at follow-up, indicating normalization of brain activation in relation to recovery. In contrast Takami et al. (Takami et al., 2007) reported attenuated activation in anterior cingulate cortex (ACC) in elderly recurrent remitted patients, when performing a verbal fluency task, with normal performance. Gyurak and colleagues (Gyurak et al., 2015) showed normal activation in DLPFC and inferior PFC and normal performance in remitted patients who had responded to antidepressive treatment. Bartova et al. (Bartova et al., 2015) reported decreased inhibition of anteromedial prefrontal cortex, an area that is activated during rest, and no differences in areas associated with cognitive effort. Thus, there exists some evidence of persisting changes in brain activation in remitted MDD, however, the direction and location of these changes is not clear. The present fMRI-study was 
conducted as a further investigation of neuronal activation in MDD patients in remission. Previous behavioral studies (Hammar et al., 2011; Årdal \& Hammar, 2011) show that this patient group has had long-lasting cognitive impairment, despite being in partial remission or in remission.

The aim of the present study was to identify the neuronal correlates of executive function in partial remitted depression, using fMRI. A particularly difficult experimental task was selected in order to manipulate cognitive load and to be more sensitive to detecting subtle abnormalities. Easy tasks may conceal cognitive deficits that would be evident in a more challenging task (Siegle et al., 2007). To maximize difficulty, two demanding tasks were combined in this study: the nback task (Braver et al., 1997) combined with Stroop test (Stroop, 1935). The Stroop stimuli were used as the target stimuli in the n-back task with the 2-back and 3-back conditions. Together, these cognitive challenges will isolate areas associated with set shifting, manipulating working memory and inhibiting responses (Griffiths et al., 2013).

The following predictions were made. Given the extremely demanding nature of the task, we hypothesized that the patient group would show neuronal hypoactivation in combination with poorer behavioural performance compared to healthy controls. The task was selected specifically to probe the functions of corticostriatal systems involved in executive functions, and we therefore used a region of interest (ROI) approach focused on the ACC, DLPFC, caudate and putamen.

\section{Method}

\section{Participants}

Twenty patients (4 males and 16 females) diagnosed with unipolar major depression were initially recruited from psychiatric institutions and clinics in order to participate in two previously published neuropsychological studies. All patients had met the DSM-IV (American Psychiatric Association, 2000) criteria for recurrent unipolar depression and had initially a minimum score of 18 on the Hamilton Depression Rating Scale (HDRS;(M. Hamilton, 1960). Current symptoms of depression were measured by the HDRS (M=7, SD= 
7) at the time of fMRI scanning. The average group scores show that the patient group had experienced symptom reduction at testing. Eleven of the patients were in remission (HDRS: $M=$ $2, \mathrm{SD}=2.5$ ) and the remaining nine patients were in symptom reduction (HDRS: $\mathrm{M}=13, \mathrm{SD}=6$ ). The age range was 21-61 years $(M=41$ years, $S D=11)$. Inclusion criteria were at least one previous episode of unipolar major depression. Exclusion criteria were previous or present psychotic symptoms, a history of manic episodes, central nervous system (CNS) lesion or disease, or any somatic condition that could interfere with cognitive functioning. There were no criteria regarding pharmacotherapy. A healthy control group of 19 subjects ( 3 males, 16 females) was recruited and matched for age $(M=40$ years, $S D=13)$ as well as gender. Control subjects did not have a history of psychiatric illness or CNS damage/disease. All participants in the study were native Norwegian speakers, and were screened for colourblindness and reading problems. 2 patients and 1 control subject had to be excluded from the data analysis due to excessive head movements in the scanner (> 3mm translation). A further subject from each group was removed from the data analysis because they gave no correct answers. Thus a total of 17 patients ( 4 male, 13 female) and 17 controls ( 3 male, 14 female) were used for the final data analysis. Before the fMRI scanning session, participants were informed about the procedure and they also received a practice session outside the scanner. They were instructed to respond as fast and as accurately as possible.

In order to control for group differences in psychomotor speed and in inhibition between groups, a Stroop paradigm was administrated before the fMRI scanning. In the present version of the Stroop-paradigm, three cards were used. All cards measured 21 x $29 \mathrm{~cm}$ and the stimuli on each card was arranged in a $6 \times 8$ matrix against a white background. The first card (colour naming) consisted of 48 colour dots (green, blue, yellow, red, white and black) and the subject was instructed to name the colour of the dots as fast as possible. On the second card (word reading) 48 words, such as green, blue, yellow, red, white or black, were written in black ink. The subject was asked to read the words as fast as possible. The third 
card (inhibition) consisted of 48 words of colour, all written in incongruent colours, such as the word "GREEN" written in red. The subject was asked to name the colour of each word, ignoring the word information, as fast as possible. Naming time, errors and self-corrected errors were scored in all three cards.

The study was performed in accordance with the Helsinki Declaration of the World Medical Association Assembly. The Regional Committee for Medical Research Ethics of Western Norway and The Norwegian Data Inspectorate had approved of the study, and written informed consent was obtained from all participants prior to testing.

\section{Stimuli and experimental design}

The task used for the experiment was a combination of a Stroop task and an n-back task (Griffiths et al., 2013). The design for each participant contained 4 sessions, one for each experimental condition. The 4 sessions were presented in 4 different orders that were counterbalanced between subjects (Table 1).

Insert Table 1 here

Each session started with an instruction screen stating whether the participant should read the word or name the print colour of the word, followed by the n-back condition (2- vs. 3-back). Within each session, 4 ON blocks and 4 OFF blocks were presented. Figure 1 shows an example of a 2-back word condition.

Insert Figure 1 here

The stimuli were the Norwegian colour-words 'RØD', 'BLÅ', 'GRØNN', 'GUL' (corresponding to 'red', 'blue', 'green' and 'yellow' in English) written in the three incongruent colours for each of the words, thus making up 12 different stimulus-words. 
The ON blocks within each session contained 24 stimuli made up of the 12 colour-words presented twice in a random order with either 3 or 4 target stimuli randomly interspersed between the non-target words depending on which n-back condition was presented. Each stimulus was presented for $2.25 \mathrm{~s}$, followed by a blank interval of $0.3 \mathrm{~s}$. Thus, the duration for an ON block was $61.2 \mathrm{~s}$ which was equally matched with the duration of the OFF blocks, during which no stimuli or task was presented. The ON and OFF blocks were repeated 4 times within each condition, making the duration of each run 8,4 min. Altogether the total duration of the experiment was $\sim 33$ minutes 4 seconds.

The presentation of the stimuli was controlled by the E-prime software (Psychology Software Tools Inc.), and MR compatible LCD "goggles" (Magnetic Resonance Technology Inc.), were used for the stimuli presentation, which were connected to a PC outside the MR chamber, which also contained the E-prime software. Responses were recorded by pressing a key on a response grip located on the chest of the participant.

For the word 2-back and 3-back runs, the participants were instructed to respond by pressing the response-grip whenever the presented word was the same as the word presented 2 or 3 trials before in the stimulus sequence. The colour 2-back and 3-back runs were analogous to the word runs, except that the instruction was to press the grip if the colour of the word presented 2 or 3 trials back was the same. Thus, the stimuli and other parameters were identical across runs, with only the instructions differing, i.e. to focus either on the semantic content (the word) or the non-semantic (print colour) content of the word.

\section{MRI scanning parameters}

Structural and functional (BOLD) data were obtained on a GE Signa HD 1.5T MR scanner, using a T1-weighted pulse sequence (FSPGR Fast Spoiled Gradient) for the structural images, with standard parameters, and an echo-planar imaging (EPI) sequence for the acquisition of the BOLD responses. The EPI sequence parameters were: repetition time (TR) $3.0 \mathrm{~s}$, scan matrix of 64 x 64 in a rectangular field of view (FOV) of $240 \mathrm{~mm}, 28$ slices with a 
slice thickness of $5 \mathrm{~mm}$ (no gap), and a reconstructed voxel size of 3.75 x 3.75 x $5 \mathrm{~mm}$. There were a total of 21 EPI whole volume scans per block, making a total of 168 scans per run, plus 5 initial dummy scans that were discarded before data analysis.

\section{Data analysis}

The fMRI data were analysed with the SPM8 software package (Wellcome Trust Centre for Neuroimaging, Department of Cognitive Neurology, Institute of Neurology, London; http://www. fil.ion.ucl.ac.uk/spm). The functional data were realigned to produce a mean image, which was then used for normalizing the images to a standard space using an EPI template. When normalizing the images the default voxel size $(2 \mathrm{~mm} \times 2 \mathrm{~mm} \times 2 \mathrm{~mm})$ and high-pass filter (128) was used. The non-linear parameters were changed to avoid overwarping of the images to the EPI template. Instead of the default 16 non-linear iterations, 3 iterations were used to partially normalize the data to avoid signal loss. The data were then smoothed with a kernel of $7.5 \mathrm{~mm} \times 7.5 \mathrm{~mm} \times 10 \mathrm{~mm}$ and put through first and second level analysis.

\section{ROI and Statistical thresholding}

Our core hypotheses concerned corticostriatal networks mediating performance of this demanding executive task. We therefore created a region of interest mask comprising the ACC, DLPFC (BA9 \& 46), caudate nucleus and putamen. This single composite mask was created by identifying these anatomically-defined regions from the Automated Anatomical Labeling (AAL) and Brodmann + atlases in the WFU_PickAtlas tool available from the SPM8 Toolbox (Maldjian, Laurienti, Kraft, \& Burdette, 2003; Tzourio-Mazoyer et al., 2002).

We report and discuss results significant at $\mathrm{p}<0.05$ family-wise error corrected for multiple comparisons within this composite a priori region, using the standard random field theory approach of SPM (Worsley et al, 2004).

Additionally we report whole brain analysis BOLD responses surviving whole brain correction at $\mathrm{p}(\mathrm{FWE})<0.05$. For information only, additional regions significant at $\mathrm{p}<0.001$ 
uncorrected in whole brain analysis are also presented in the Tables although we do not attempt to interpret these results.

\section{Statistical analysis of behavioural data}

A mixed-factorial ANOVA was run on the behavioural data, separately for reaction time (RT) and response accuracy (RA) data, with the factors INSTRUCTION (report the word or the print colour of the word), LOAD (2-back or 3-back), and GROUP (controls and patients). The first two factors were treated as within-group factors in the ANOVA, while the third factor was treated as a between-group factor.

\section{Results}

\section{Neuropsychological data (Stroop):}

An independent-sample t-test was conducted to compare the Stroop scores for the both groups. There was no significant difference in scores for patients on the condition colour naming $(M=27.95, S D=6.48)$ and healthy controls $(M=24.95, S D=4.27 ; t(36)=1.68$, $\mathrm{p}=.10$, two-tailed $)$, or the condition word reading $(\mathrm{M}=17.37, \mathrm{SD}=1.98)$ and healthy controls $(\mathrm{M}=16.26, \mathrm{SD}=1.7 ; \mathrm{t}(36)=1.83, \mathrm{p}=.08$, two-tailed $)$. There was, however, a significant difference in scores for patients on the condition inhibition $(M=46.79, \mathrm{SD}=13.78)$ and healthy controls $(\mathrm{M}=38.16, \mathrm{SD}=7.99 ; \mathrm{t}(36)=2.36, \mathrm{p}=.02$, two-tailed $)$. Relation between cognitive impairment and illness severity was investigated using Pearson product-moment correlation coefficient. Preliminary analyses were performed to ensure no violation of the assumptions of normality, linearity and homoscedasticity. There was no significant correlation between illness severity and inhibition in the patient group, $r=.031, n=19, p<.05$.

\section{Behavioural data: Reaction Time (RT)}

The omnibus ANOVA showed significant main-effects of GROUP, $F(1,36)=4.12$, $p$ $<0.05$, with longer RTs in the patient group, and of $\operatorname{LOAD}, \mathrm{F}(1,36)=28.17 ; \mathrm{p}<.0001$, with longer RTs for the 3-back condition compared to the 2-back condition. Moreover, the twoway interactions of GROUP x INSTRUCTION, $\mathrm{F}(1,36)=4.30, \mathrm{p}<.05$, and GROUP $\mathrm{x}$ 
LOAD, $\mathrm{F}(1,36)=4.22, \mathrm{p}<.05$ were significant. The interactions were followed-up with analysis of simple main effects using Fischer's LSD test $(\mathrm{p}<.05$ threshold for all comparisons). These follow-up analyses showed that the control subjects had significantly longer RTs for the colour compared to the word instruction $(\mathrm{p}<.05)$, while the patients did not differ between conditions, with equally long RTs for both conditions (Figure 2a).

Insert Figure 2a here

For the GROUP x LOAD interaction, the follow-up analysis showed that the controls had significantly shorter RTs compared to the patients for the 2-back condition, and that they also had longer RTs for the 3- compared to the 2-back condition, while the patients did not differ significantly for the 2- and 3-back conditions, however, the mean RT was longer in the 3-back condition (Figure 2b).

Insert Figure $2 b$ here

\section{Behavioural data: Response accuracy (RA)}

The omnibus ANOVA showed significant main-effects of $\operatorname{LOAD}, \mathrm{F}(1,36)=32.88$, $\mathrm{p}<$ .0001 , with reduced RA for the 3-back condition compared to the 2-back condition (Figure 3a-b), and of INSTRUCTION, F(1,36) $=10.27, \mathrm{p}<.01$, with reduced RA for the colour condition compared to the word condition. There was also a marginal effect for GROUP, $\mathrm{F}(1,36)=3.26, \mathrm{p}=.08$, with the patients showing reduced RA compared to the controls. The difference was significant, $\mathrm{p}<.05$, with a one-tailed test, which would be justified considering the direction of the hypothesis for this factor. None of the two-way interactions were significant (Figure 3a-b). 
Insert Figure $3 \mathrm{a}$ and $\mathrm{b}$ here

\title{
fMRI results
}

The fMRI results are first presented for the colour and word conditions for the control group. We then present the corresponding patient data, first comparing the activation of each group separately, followed by the control group activation subtracted from the patient group activation, and vice versa.

\section{Control Group Data for Colour and Word conditions}

Results for colour (2-back and 3-back combined) vs rest are shown in Table 2.

\author{
Insert Table 2 here
}

Significant areas of activation were found bilaterally in the DLPFC (BA9 and 46) and the right putamen, with bilateral caudate activation just failing to reach significance. The contrast of word vs rest is shown in Table 3 .

\section{Insert Table 3 here}

This contrast found significant activations in the left DLPFC (BA9/46) and the right putamen.

The colour and word conditions were then contrasted against each other. There were no differential activations for word vs. colour or colour vs. word, either within the ROI or for the whole brain analysis, even when the threshold was reduced to $\mathrm{p}<0.001$ uncorrected. 
The 2-back and 3-back conditions (with colour and word combined) were then contrasted against rest and each other. Table 4 shows results for the 2-back condition versus rest.

Insert Table 4 here

As shown in Table 4, only the left and right DLPFC (BA9) and the right putamen showed clusters of activation that were significant after correction, although bilateral caudate activation was also observed at a lower level of statistical significance. Results for the 3-back condition contrasted against rest are shown in Table 5.

Insert Table 5 here

The 3-back versus rest contrast showed significant areas of activation in the left DLPFC (BA46), and the right DLPFC (BA9) and bilaterally in the putamen.

The 2-back and 3-back conditions were then compared against each other and no differences were seen even at the more lenient threshold of $p<0.001$ uncorrected.

\section{Comparing patients and controls}

Having established a corticostriatal network mediating task performance in the control group as a baseline, we then used between-group comparisons to identify regions where activations in the patient group differed significantly from that observed in the controls. Differential activations for colour and word conditions vs. rest are shown in Table 6 and Figure 4.

Insert Table 6 here

Insert Figure $4 \mathrm{a}$ and $\mathrm{b}$ here 
Figure $4 \mathrm{a}$ and $\mathrm{b}$ and Table 6 show that for the colour versus rest condition there was significantly reduced right caudate activation in patients relative to controls at a corrected significance level. At a lower threshold, reduced left caudate activation was also observed. For the word versus rest contrast, there were no differences at the corrected significance level, although at the less stringent level, reduced bilateral caudate and putamen activation was seen in the patients.

For direct comparisons between colour and word conditions, there were no differences between patients and controls, even at the lower level of significance.

\section{Contrasts for n-back conditions}

Finally between-group differences for 2-back and 3-back versus rest were analysed, see Table 7 and Figure 5.

Insert Table 7 here

Insert Figure 5a and $\mathrm{b}$ here

There were no significant differences between groups at $\mathrm{p}<0.05$ corrected levels. However, patients showed reduced bilateral caudate activation for 2-back vs rest and reduced left caudate activation for 3-back vs. rest at a lower level of significance, $(\mathrm{p}<.001$ uncorrected).

When comparing the 2-back and 3-back conditions directly, there were no differences between patients and controls, even at the lower level of significance.

There were no significant correlations with either response accuracy or response latency in any of the regions activated by the tasks and instructions. Further, there were no correlations between Hamilton scores and behavioural or functional data.

\section{Discussion}


In the present study, we investigated neural response in corticostriatal circuits involved in executive functioning using a task combining n-back task and Stroop components during functional imaging. The major finding of this study is that a sample of remitted and partial remitted MDD patients exhibited normal activity in DLPFC and ACC along with hypoactivity of the striatum, particularly in the caudate nucleus, in contrast to never-depressed controls. Behavioural performance was also impaired in the patient group. There were no significant correlations between brain responses and behavioural data.

There is no reason to assume that findings on the behavioural data for the fMRI-paradigm were a result of psychomotor retardation in the patient group. In the Stroop test, the first two conditions (colour naming and word reading) measure psychomotor tempo, and in our study no such differences between groups were found. Further there was no indication that cognitive impairment was related to illness severity.

The behavioural results showed that the patients overall were both slower in initiating a response, and less accurate than the control subjects. This is contrasting to some recent studies showing no differences in performance between controls and partial remitted MDD, using the n-back task (Bartova et al., 2015; Gyurak et al., 2015). However, our results are in line with recent meta-analyses showing significant deficits in executive function in remitted MDD (E Bora et al., 2013; Rock et al., 2014). Differences in results may be due to the heterogeneity of MDD (E Bora et al., 2013) and different subgroups may show varying levels of persisting cognitive deficits.

Both groups were sensitive to the manipulation of working memory load and the instructions of stimulus characteristic, with overall longer RT for the 3-back compared to the 2-back condition, and for the colour compared to the word condition. A comparison between the groups showed that the difference between groups was larger for the word compared to the colour instruction, and for the 2-back compared to the 3-back working memory load. 
In the control group, the fMRI results indicated activation in a corticostriatal network associated with performance of this demanding executive task. All four conditions compared to rest were associated with activations in bilateral DLPFC and striatal regions (caudate and/or putamen), with ACC activation additionally observed in the 3-back condition. When directly comparing the $\mathrm{C} 2, \mathrm{C} 3, \mathrm{~W} 2$ and $\mathrm{W} 3$ contrasts against each other, there were no significant differences, indicating a common pattern of activation for all conditions. These frontal and striatal regions are part of well-established corticostriatal networks implicated in executive functions (Duncan \& Owen, 2000; J. P. Hamilton et al., 2012; Tekin \& Cummings, 2002).

At a neuronal level, previous studies have suggested either hypoactivation in depression during performance of executive tasks (typically accompanied by impaired performance), or hyperactivation (typically accompanied by normal performance). Our findings are more in line with a hypoactivation account. The control group had longer RT for the colour condition compared to the word condition, indicating that the colour instruction was more challenging than the word instruction. The patient group had similar RTs for both conditions. This may suggest that the patient group were unable to recruit the additional resources required by the colour instruction, which may explain why the imaging results were mainly seen in the colour paradigm.

The present study showed no areas of hyperactivation in the patient group relative to controls for any of the contrasts, perhaps because the task was so difficult that the patient group were unable to recruit additional neuronal resources to achieve control levels of performance. This finding therefore supports previous studies showing that increased prefrontal activation during cognitive tasks is evident only when normal cognitive performance is achieved (Fitzgerald et al., 2008; Harvey et al., 2005; Wagner et al., 2006), which is not the case here.

The present study found hypoactivation in striatal regions of executive networks. When each task condition was compared to rest, patients showed hypoactivation in the caudate, which reached significance for the colour versus rest contrast. Thus, the results indicate that poorer 
behavioural performance in the patient group is associated with neuronal hypoactivation. There were no differences in DLPFC activation between the patients and controls, despite the behavioural difference. A few recent studies have found similar results. Gyurak and colleagues (Gyurak et al., 2015) also found normal activation in DLPFC in a sample of remitted MDD patients during executive tasks. However, they found no difference in behavioural performance. Rodríguez-Cano and colleagues (2014) found hypoactivation of the left caudate nucleus together with poorer performance in the depressed sample. This hypoactivation was, however, not exclusive to the caudate, but included DLPFC and other areas.

Thus, there is some evidence for altered striatal activity associated with cognitive deficits in MDD and the present study adds to this evidence. Further, studies using emotional and rewardrelated stimuli have found attenuated activation in dorsal striatum in depressed samples (Connolly, Gollan, Cobia, \& Wang, 2015; J. P. Hamilton et al., 2012; Marchand \& YurgelunTodd, 2010; Pizzagalli et al., 2009). Taken together, these studies make a strong argument for a role of altered striatal activation in MDD. The present pilot study point to lasting striatal activation alterations despite remission, however, this needs to be further investigated in a longitudinal study.

One further possible link between depression, cognition and the striatum is based on the observation that basal ganglia disorders, like Huntington's disease (HD) and Parkinson's disease (PD) are associated both with cognitive decline and depressive symptoms (Marchand, 2010; Marchand \& Yurgelun- Todd, 2010; Slaughter, Martens, \& Slaughter, 2001; Weintraub \& Stern, 2005). The cognitive deficits seen in these diseases are intimately associated with striatal atrophy (Rebecca Elliott, 2003). Striatal atrophy have also been linked to MDD in several studies and meta-analyses (Arnone, McIntosh, Ebmeier, Munafo, \& Anderson, 2012; Emre Bora, Harrison, Davey, Yücel, \& Pantelis, 2012; Kim, Hamilton, \& Gotlib, 2008; Koolschijn et al., 2009; Macfarlane et al., 2013; Marchand \& YurgelunTodd, 2010; Pizzagalli et al., 2009). For example, Kim and colleagues (Kim et al., 2008) found reduced volume of the caudate nucleus in women 
suffering from major depression and suggested that this reduced volume may explain the disruption of corticostriatal circuits. Macfarlene and colleagues (Macfarlane et al., 2013) found that poorer executive performance was correlated with smaller caudate volume, lending evidence for an overlap of striatal volume and cognitive function. Striatal atrophy is likely to be associated with loss of medial spiny neurons (MSNs; (Marchand \& Yurgelun- Todd, 2010). These neurons make up 75-80 \% of striatal neurons (Cicchetti, Prensa, Wu, \& Parent, 2000) and activity in the striatum shown in fMRI may be interpreted as representing firing of MSNs (Marchand \& Yurgelun- Todd, 2010). Thus, the decreased activity in caudate nucleus observed in the present study may be linked to decreased firing of MSNs.

Taken together, there are strong indications for a role of the striatum in MDD and the present study adds to this. Further, the present findings indicate lasting neuronal alteration or 'scarring' due to MDD. Scarring theories suggest that an episode of depression cause changes at a biological level and that this change increase the vulnerability to recurrent episodes (Burcusa \& Iacono, 2007). However, a common argument against scarring theories is that individuals may already have the characteristics or trait that make them vulnerable to recurrent depression before their first episode (Burcusa \& Iacono, 2007). The discussion of trait vs scarring effects is beyond the scope of this paper.

The results of the present study show striatal hypoactivity during cognitive effort, accompanied by poorer behavioural performance in a sample of remitted and partial remitted depressed participants compared to a sample of never-depressed participants. Several hypothesized mechanisms involved in this hypoactivity have been presented. The present study shows that altered activity in brain regions associated with cognition, as shown in previous studies of depression, persist despite symptom alleviation. It is possible that, despite remission, performance is impaired and the disorder leaves 'scars' in brain tissue.

Further research is needed to elucidate the link between altered activation, volumetric changes, and potential neuronal degeneration of the striatum and how such changes may be 
associated with the clinical symptoms and cognitive impairment in the different phases of major depression.

\section{Limitations}

This study does have a few limitations. The main limitation is the small sample. Therefore, independent replication would be needed to confirm the findings. Further replications of the study may also improve the power of the results if similar activations are found.

Further, we could not rule out any medication effects on the results. From previous studies using the same patient group, it is clear that some participants received pharmacological antidepressant treatment at testing (Hammar et al., 2011; Årdal \& Hammar, 2011). This may have affected the results. For example, two recent meta-analyses indicate that some types of antidepressants may have a small positive effect on cognitive function (Keefe et al., 2014; Rosenblat, Kakar, \& McIntyre, 2015). Future research should take medication status into account.

Further, areas beyond the ROI used in the present study may be involved in deficits in working memory and executive function observed in psychiatric disease. For example, the ventral PFC has been implicated in poorer n-back performance in schizophrenic patients (Tan et al., 2006). A whole-brain analysis approach would be more suited to investigate the possible role of other brain areas in executive dysfunction in depression.

Another potential limitation is the absence of a 0-back condition, which would contain only attention, but no working memory ore xecutive demands. The reason we did not include a 0-back condition was not to prolong the scanning session with the risk of inducing fatigueeffects at the end of the session, which could have affected the depressed and control groups differentially, causing an unwanted interaction-effect. A second reason was that the study was not about separating attention and other effects, but rather to contrast two conditions where attention demands would be rather constant but which differed in working memory and executive demands. 
As the results from this investigation opens questions about the scarring effect of psychiatric disorders, further investigation into this patient group would be beneficial for clinical applications as well as future research of the neuronal correlates of executive function. By investigating whether the scarring is a cause or an effect of the disorder, it would further clinical knowledge on the trait effects and predispositions to psychiatric disorders such as MDD.

\section{Conclusion}

The present study showed striatal hypoactivation and impaired cognitive performance in a sample of partial remitted MDD patients compared to never-depressed controls, indicating neuronal scarring from the disorder. The study contributes to the scarce literature on neuronal correlates of executive impairment in partial remitted MDD. The persisting neuronal alteration and cognitive impairment seen in the present study highlights the importance of preventing and treating MDD, as the disorder may leave neuronal, as well as behavioural, scars. 


\section{References}

\section{References}

Airaksinen, E., Wahlin, Å., Larsson, M., \& Forsell, Y. (2006). Cognitive and social functioning in recovery from depression: Results from a population-based three-year follow-up. Journal of affective disorders, 96(1-2), 107-110. doi:http://dx.doi.org/10.1016/j.jad.2006.05.004

Aizenstein, H. J., Butters, M. A., Figurski, J. L., Stenger, V. A., Reynolds Iii, C. F., \& Carter, C. S. (2005). Prefrontal and Striatal Activation During Sequence Learning in Geriatric Depression. Biological Psychiatry, 58(4), 290-296.

doi:http://dx.doi.org/10.1016/j.biopsych.2005.04.023

American Psychiatric Association. (2000). Diagnostic and statistical manual of mental disorders. Washington, DC.

Arnone, D., McIntosh, A., Ebmeier, K., Munafo, M., \& Anderson, I. (2012). Magnetic resonance imaging studies in unipolar depression: systematic review and metaregression analyses. European Neuropsychopharmacology, 22(1), 1-16.

Bartova, L., Meyer, B. M., Diers, K., Rabl, U., Scharinger, C., Popovic, A., . . Huemer, J. (2015). Reduced default mode network suppression during a working memory task in remitted major depression. Journal of psychiatric research, 64, 9-18.

Biringer, E., Lundervold, A., Stordal, K., Mykletun, A., Egeland, J., Bottlender, R., \& Lund, A. (2005). Executive function improvement upon remission of recurrent unipolar depression. European Archives of Psychiatry and Clinical Neuroscience, 255(6), 373380.

Bora, E., Harrison, B., Davey, C., Yücel, M., \& Pantelis, C. (2012). Meta-analysis of volumetric abnormalities in cortico-striatal-pallidal-thalamic circuits in major depressive disorder. Psychological medicine, 42(04), 671-681. 
Bora, E., Harrison, B., Yücel, M., \& Pantelis, C. (2013). Cognitive impairment in euthymic major depressive disorder: a meta-analysis. Psychological medicine, 43(10), 20172026.

Braver, T. S., Cohen, J. D., Nystrom, L. E., Jonides, J., Smith, E. E., \& Noll, D. C. (1997). A parametric study of prefrontal cortex involvement in human working memory. Neuroimage, 5(1), 49-62.

Burcusa, S. L., \& Iacono, W. G. (2007). Risk for recurrence in depression. Clinical psychology review, 27(8), 959-985.

Castaneda, A. E., Tuulio-Henriksson, A., Marttunen, M., Suvisaari, J., \& Lönnqvist, J. (2008). A review on cognitive impairments in depressive and anxiety disorders with a focus on young adults. Journal of affective disorders, 106(1), 1-27.

Chudasama, Y., \& Robbins, T. (2006). Functions of frontostriatal systems in cognition: comparative neuropsychopharmacological studies in rats, monkeys and humans. Biological psychology, 73(1), 19-38.

Cicchetti, F., Prensa, L. a., Wu, Y., \& Parent, A. (2000). Chemical anatomy of striatal interneurons in normal individuals and in patients with Huntington's disease. Brain research reviews, 34(1), 80-101.

Connolly, M. E., Gollan, J. K., Cobia, D., \& Wang, X. (2015). Reduced striatal activation in females with major depression during the processing of affective stimuli. Journal of psychiatric research.

Diener, C., Kuehner, C., Brusniak, W., Ubl, B., Wessa, M., \& Flor, H. (2012). A metaanalysis of neurofunctional imaging studies of emotion and cognition in major depression. Neuroimage, 61(3), 677-685.

Drevets, W. C. (2000). Neuroimaging studies of mood disorders. Biological Psychiatry, $48(8), 813-829$. 
Duncan, J., \& Owen, A. M. (2000). Common regions of the human frontal lobe recruited by diverse cognitive demands. Trends in neurosciences, 23(10), 475-483.

Elliot, R., \& Dolan, R. J. (2002). Functional neuroimaging of depression: a role for medial prefrontal cortex. Handbook of affective sciences, 117-128.

Elliott, R. (2003). Executive functions and their disorders Imaging in clinical neuroscience. British medical bulletin, 65(1), 49-59.

Elliott, R., Baker, S., Rogers, R., O'leary, D., Paykel, E., Frith, C., . . Sahakian, B. (1997). Prefrontal dysfunction in depressed patients performing a complex planning task: a study using positron emission tomography. Psychological medicine, 27(04), 931-942.

Fitzgerald, P. B., Srithiran, A., Benitez, J., Daskalakis, Z. Z., Oxley, T. J., Kulkarni, J., \& Egan, G. F. (2008). An fMRI study of prefrontal brain activation during multiple tasks in patients with major depressive disorder. Human Brain Mapping, 29(4), 490-501.

Furman, D. J., Hamilton, J. P., \& Gotlib, I. H. (2011). Frontostriatal functional connectivity in major depressive disorder. Biology of mood \& anxiety disorders, 1(1), 1-11.

Griffiths, S. T., Gundersen, H., Neto, E., Elgen, I., Markestad, T., Aukland, S. M., \& Hugdahl, K. (2013). fMRI: blood oxygen level-dependent activation during a working memory-selective attention task in children born extremely preterm. Pediatric research, 74(2), 196-205.

Gruber, S., Rathgeber, K., Bräunig, P., \& Gauggel, S. (2007). Stability and course of neuropsychological deficits in manic and depressed bipolar patients compared to patients with major depression. Journal of affective disorders, 104(1), 61-71.

Gyurak, A., Patenaude, B., Korgaonkar, M. S., Grieve, S. M., Williams, L. M., \& Etkin, A. (2015). Frontoparietal Activation During Response Inhibition Predicts Remission to Antidepressants in Patients with Major Depression. Biological Psychiatry. 
Hamilton, J. P., Etkin, A., Furman, D. J., Lemus, M. G., Johnson, R. F., \& Gotlib, I. H. (2012). Functional Neuroimaging of Major Depressive Disorder: A Meta-Analysis and New Integration of Baseline Activation and Neural Response Data. American Journal of Psychiatry, 169(7), 693-703. doi:doi:10.1176/appi.ajp.2012.11071105

Hamilton, M. (1960). A rating scale for depression. Journal of neurology, neurosurgery, and psychiatry, 23(1), 56.

Hammar, Å., Lund, A., \& Hugdahl, K. (2003). Long-lasting cognitive impairment in unipolar major depression: a 6-month follow-up study. Psychiatry research, 118(2), 189-196.

Hammar, Å., \& Schmid, M. (2013). Visual memory performance in patients with major depression: a 9-month follow-up. Applied Neuropsychology: Adult, 20(3), 192-196.

Hammar, A., Strand, M., Årdal, G., Schmid, M., Lund, A., \& Elliott, R. (2011). Testing the cognitive effort hypothesis of cognitive impairment in major depression. Nordic journal of psychiatry, 65(1), 74-80.

Hammar, Å., SØRensen, L., Årdal, G., Oedegaard, K. J., Kroken, R., Roness, A., \& Lund, A. (2010). Enduring cognitive dysfunction in unipolar major depression: a test-retest study using the Stroop paradigm. Scandinavian journal of psychology, 51(4), 304-308.

Hammar, A., \& Årdal, G. (2009). Cognitive functioning in major depression-a summary. Frontiers in human neuroscience, 3.

Hammar, Å., \& Årdal, G. (2012). Effortful information processing in patients with major depression-A 10-year follow-up study. Psychiatry research, 198(3), 420-423.

Hammar, Å., \& Årdal, G. (2013). Verbal memory functioning in recurrent depression during partial remission and remission- Brief report. Frontiers in Psychology, 4. doi:10.3389/fpsyg.2013.00652 
Harvey, P.-O., Fossati, P., Pochon, J.-B., Levy, R., LeBastard, G., Lehéricy, S., . . Dubois, B. (2005). Cognitive control and brain resources in major depression: an fMRI study using the n-back task. Neuroimage, 26(3), 860-869.

Hasselbalch, B. J., Knorr, U., \& Kessing, L. V. (2011). Cognitive impairment in the remitted state of unipolar depressive disorder: a systematic review. Journal of affective disorders, 134(1), 20-31.

Hugdahl, K., Rund, B. R., Lund, A., Asbjørnsen, A., Egeland, J., Ersland, L., . . Thomsen, T. (2004). Brain Activation Measured With fMRI During a Mental Arithmetic Task in Schizophrenia and Major Depression. American Journal of Psychiatry, 161(2), 286293. doi:doi:10.1176/appi.ajp.161.2.286

Hugdahl, K., Specht, K., Biringer, E., Weis, S., Elliott, R., Hammar, Å., . . Lund, A. (2007). Increased parietal and frontal activation after remission from recurrent major depression: a repeated fMRI study. Cognitive therapy and research, 31(2), 147-160.

Keefe, R., McClintock, S. M., Roth, R. M., Doraiswamy, P. M., Tiger, S., \& Madhoo, M. (2014). Cognitive effects of pharmacotherapy for major depressive disorder: a systematic review. The Journal of clinical psychiatry, 75(8), 864-876.

Kim, M. J., Hamilton, J. P., \& Gotlib, I. H. (2008). Reduced caudate gray matter volume in women with major depressive disorder. Psychiatry Research: Neuroimaging, 164(2), 114-122.

Koetsier, G. C., Volkers, A. C., Tulen, J. H., Passchier, J., van den Broek, W. W., \& Bruijn, J. A. (2002). CPT performance in major depressive disorder before and after treatment with imipramine or fluvoxamine. Journal of psychiatric research, 36(6), 391-397.

Koolschijn, P., van Haren, N. E., Lensvelt-Mulders, G. J., Pol, H., Hilleke, E., \& Kahn, R. S. (2009). Brain volume abnormalities in major depressive disorder: A meta-analysis of magnetic resonance imaging studies. Human Brain Mapping, 30(11), 3719-3735. 
Lahr, D., Beblo, T., \& Hartje, W. (2007). Cognitive performance and subjective complaints before and after remission of major depression. Cognitive neuropsychiatry, 12(1), 2545.

Langenecker, S. A., Kennedy, S. E., Guidotti, L. M., Briceno, E. M., Own, L. S., Hooven, T., . . Zubieta, J.-K. (2007). Frontal and limbic activation during inhibitory control predicts treatment response in major depressive disorder. Biological Psychiatry, 62(11), 1272-1280.

Macfarlane, M. D., Looi, J. C. L., Walterfang, M., Spulber, G., Velakoulis, D., Crisby, M., .. . Waldemar, G. (2013). Executive dysfunction correlates with caudate nucleus atrophy in patients with white matter changes on MRI: A subset of LADIS. Psychiatry Research: Neuroimaging, 214(1), 16-23.

Majer, M., Ising, M., Künzel, H., Binder, E., Holsboer, F., Modell, S., \& Zihl, J. (2004). Impaired divided attention predicts delayed response and risk to relapse in subjects with depressive disorders. Psychological medicine, 34(08), 1453-1463.

Maldjian, J. A., Laurienti, P. J., Kraft, R. A., \& Burdette, J. H. (2003). An automated method for neuroanatomic and cytoarchitectonic atlas-based interrogation of fMRI data sets. Neuroimage, 19(3), 1233-1239.

Marchand, W. R. (2010). Cortico-basal ganglia circuitry: a review of key research and implications for functional connectivity studies of mood and anxiety disorders. Brain Structure and Function, 215(2), 73-96.

Marchand, W. R., \& Yurgelun-Todd, D. (2010). Striatal structure and function in mood disorders: a comprehensive review. Bipolar disorders, 12(8), 764-785.

Mayberg, H. S., Liotti, M., Brannan, S. K., McGinnis, S., Mahurin, R. K., Jerabek, P. A., . . . Fox, P. T. (1999). Reciprocal Limbic-Cortical Function and Negative Mood: 
Converging PET Findings in Depression and Normal Sadness. American Journal of Psychiatry, 156(5), 675-682. doi:doi:10.1176/ajp.156.5.675

Nakano, Y., Baba, H., Maeshima, H., Kitajima, A., Sakai, Y., Baba, K., . . Arai, H. (2008). Executive dysfunction in medicated, remitted state of major depression. Journal of affective disorders, 111(1), 46-51.

Neu, P., Bajbouj, M., Schilling, A., Godemann, F., Berman, R. M., \& Schlattmann, P. (2005). Cognitive function over the treatment course of depression in middle-aged patients: correlation with brain MRI signal hyperintensities. Journal of psychiatric research, $39(2), 129-135$.

Okada, G., Okamoto, Y., Morinobu, S., Yamawaki, S., \& Yokota, N. (2003). Attenuated left prefrontal activation during a verbal fluency task in patients with depression. Neuropsychobiology, 47(1), 21-26.

Paelecke-Habermann, Y., Pohl, J., \& Leplow, B. (2005). Attention and executive functions in remitted major depression patients. Journal of affective disorders, 89(1-3), 125-135. doi:http://dx.doi.org/10.1016/j.jad.2005.09.006

Pizzagalli, D. A., Holmes, A. J., Dillon, D. G., Goetz, E. L., Birk, J. L., Ryan Bogdan, A., . . . Fava, M. (2009). Reduced caudate and nucleus accumbens response to rewards in unmedicated individuals with major depressive disorder. The American journal of psychiatry, 166(6), 702-710.

Reischies, F. M., \& Neu, P. (2000). Comorbidity of mild cognitive disorder and depression-a neuropsychological analysis. European Archives of Psychiatry and Clinical Neuroscience, 250(4), 186-193.

Rock, P., Roiser, J., Riedel, W., \& Blackwell, A. (2014). Cognitive impairment in depression: a systematic review and meta-analysis. Psychological medicine, 44(10), 2029-2040. 
Rodríguez-Cano, E., Sarró, S., Monté, G., Maristany, T., Salvador, R., McKenna, P., \& Pomarol-Clotet, E. (2014). Evidence for structural and functional abnormality in the subgenual anterior cingulate cortex in major depressive disorder. Psychological medicine, 44(15), 3263-3273.

Rogers, M. A., Kasai, K., Koji, M., Fukuda, R., Iwanami, A., Nakagome, K., . . Kato, N. (2004). Executive and prefrontal dysfunction in unipolar depression: a review of neuropsychological and imaging evidence. Neuroscience research, 50(1), 1-11.

Rosenblat, J. D., Kakar, R., \& McIntyre, R. S. (2015). The Cognitive Effects of Antidepressants in Major Depressive Disorder: A Systematic Review and MetaAnalysis of Randomized Clinical Trials. International Journal of Neuropsychopharmacology, pyv082.

Schmid, M., Strand, M., Årdal, G., Lund, A., \& Hammar, Å. (2011). Prolonged impairment in inhibition and semantic fluency in a follow-up study of recurrent major depression. Archives of clinical neuropsychology, 26(7), 677-686.

Siegle, G. J., Thompson, W., Carter, C. S., Steinhauer, S. R., \& Thase, M. E. (2007). Increased amygdala and decreased dorsolateral prefrontal BOLD responses in unipolar depression: related and independent features. Biological Psychiatry, 61(2), 198-209.

Slaughter, J. R., Martens, M. P., \& Slaughter, K. A. (2001). Depression and Huntington's disease: prevalence, clinical manifestations, etiology, and treatment. CNS spectrums, 6(04), 306-308,325-326.

Smith, D. J., Muir, W. J., \& Blackwood, D. H. (2006). Neurocognitive impairment in euthymic young adults with bipolar spectrum disorder and recurrent major depressive disorder. Bipolar disorders, 8(1), 40-46. 
Snyder, H. R. (2013). Major depressive disorder is associated with broad impairments on neuropsychological measures of executive function: a meta-analysis and review. Psychological bulletin, 139(1), 81.

Stroop, J. R. (1935). Studies of interference in serial verbal reactions. Journal of experimental psychology, 18(6), 643.

Takami, H., Okamoto, Y., Yamashita, H., Okada, G., \& Yamawaki, S. (2007). Attenuated anterior cingulate activation during a verbal fluency task in elderly patients with a history of multiple-episode depression. The American journal of geriatric psychiatry, 15(7), 594-603.

Tan, H.-Y., Sust, S., Buckholtz, J. W., Mattay, V. S., Meyer-Lindenberg, A., Egan, M. F., . . Callicott, J. H. (2006). Dysfunctional prefrontal regional specialization and compensation in schizophrenia. American Journal of Psychiatry.

Tekin, S., \& Cummings, J. L. (2002). Frontal-subcortical neuronal circuits and clinical neuropsychiatry: an update. Journal of psychosomatic research, 53(2), 647-654.

Thomas, E. J., \& Elliott, R. (2009). Brain imaging correlates of cognitive impairment in depression. Frontiers in human neuroscience, 3.

Tzourio-Mazoyer, N., Landeau, B., Papathanassiou, D., Crivello, F., Etard, O., Delcroix, N., . . Joliot, M. (2002). Automated anatomical labeling of activations in SPM using a macroscopic anatomical parcellation of the MNI MRI single-subject brain. Neuroimage, 15(1), 273-289.

Wagner, G., Sinsel, E., Sobanski, T., Köhler, S., Marinou, V., Mentzel, H.-J., . . S Schlösser, R. G. (2006). Cortical inefficiency in patients with unipolar depression: an eventrelated FMRI study with the Stroop task. Biological Psychiatry, 59(10), 958-965. 
Walter, H., Wolf, R. C., Spitzer, M., \& Vasic, N. (2007). Increased left prefrontal activation in patients with unipolar depression: an event-related, parametric, performancecontrolled fMRI study. Journal of affective disorders, 101(1), 175-185.

Weiland-Fiedler, P., Erickson, K., Waldeck, T., Luckenbaugh, D. A., Pike, D., Bonne, O., . . . Neumeister, A. (2004). Evidence for continuing neuropsychological impairments in depression. Journal of affective disorders, 82(2), 253-258.

Weintraub, D., \& Stern, M. B. (2005). Psychiatric complications in Parkinson disease. The American journal of geriatric psychiatry, 13(10), 844-851.

Wekking, E. M., Bockting, C. L., Koeter, M. W., \& Schene, A. H. (2012). Cognitive functioning in euthymic recurrently depressed patients: Relationship with future relapses and prior course of disease. Journal of affective disorders, 141(2), 300-307.

Årdal, G., \& Hammar, Å. (2011). Is impairment in cognitive inhibition in the acute phase of major depression irreversible? Results from a 10-year follow-up study. Psychology and Psychotherapy: Theory, Research and Practice, 84(2), 141-150. 


\section{Tables}

Table 1: Counter-balanced order of conditions

\begin{tabular}{lllll} 
& Session 1 & Session 2 & Session 3 & Session 4 \\
\hline Order 1 & Word 2-back & Word 3-back & Colour 2-back & Colour 3-back \\
\hline Order 2 & Colour 2-back & Colour 3-back & Word 2-back & Word 3-back \\
\hline Order 3 & Word 3-back & Colour 3-back & Word 2-back & Colour 2-back \\
\hline Order 4 & Colour 3-back & Word 3-back & Colour 2-back & Word 2-back \\
& & & & \\
\hline
\end{tabular}


Table 2: Control group activation for Colour versus rest, with ROI mask. Uncorrected threshold $\mathrm{p}<0.001$, cluster extent level $=5$ voxels.

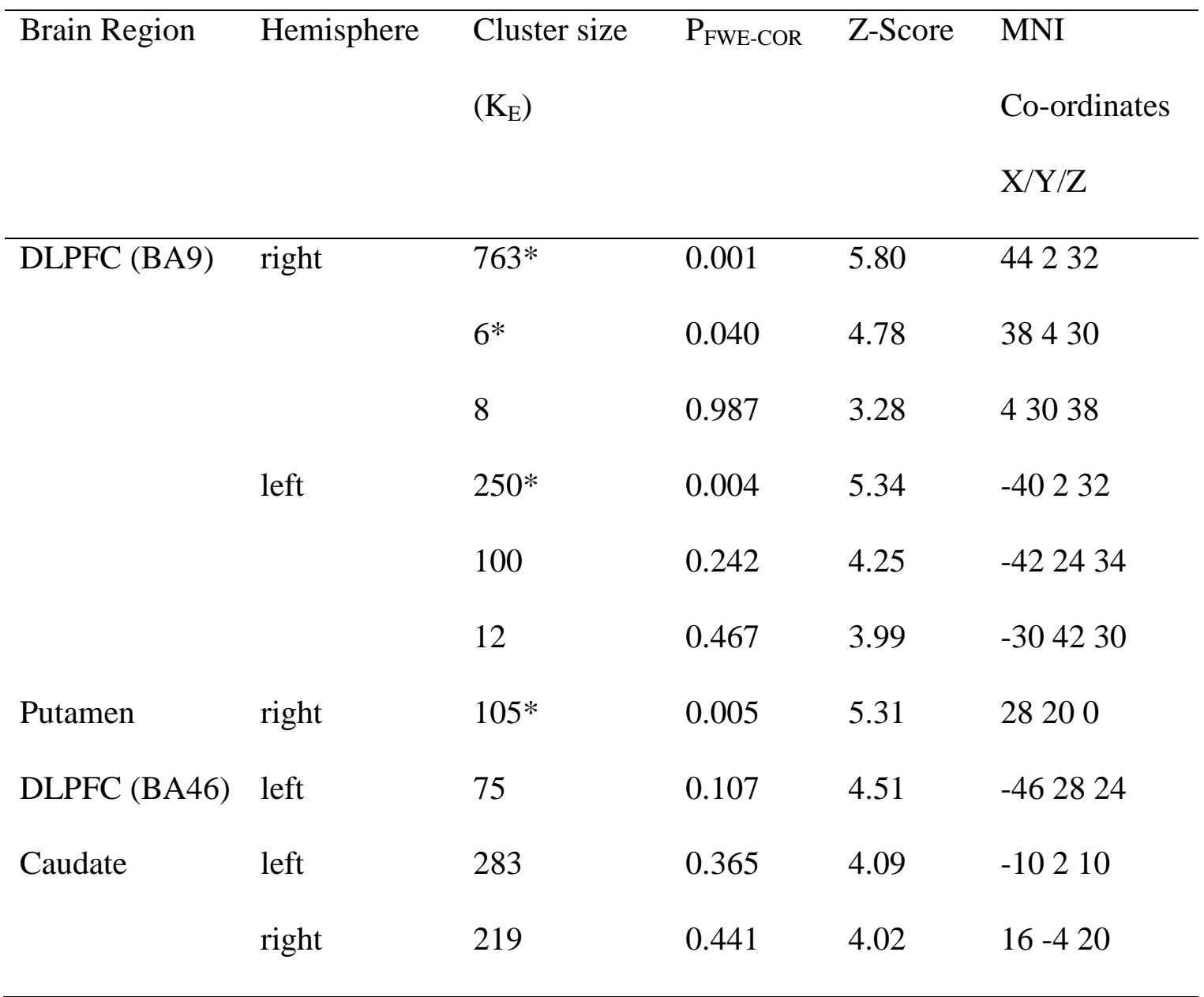


Table 3: Control group activation for Word versus rest, with ROI mask. Uncorrected threshold $\mathrm{p}<0.001$, cluster extent level $=5$ voxels.

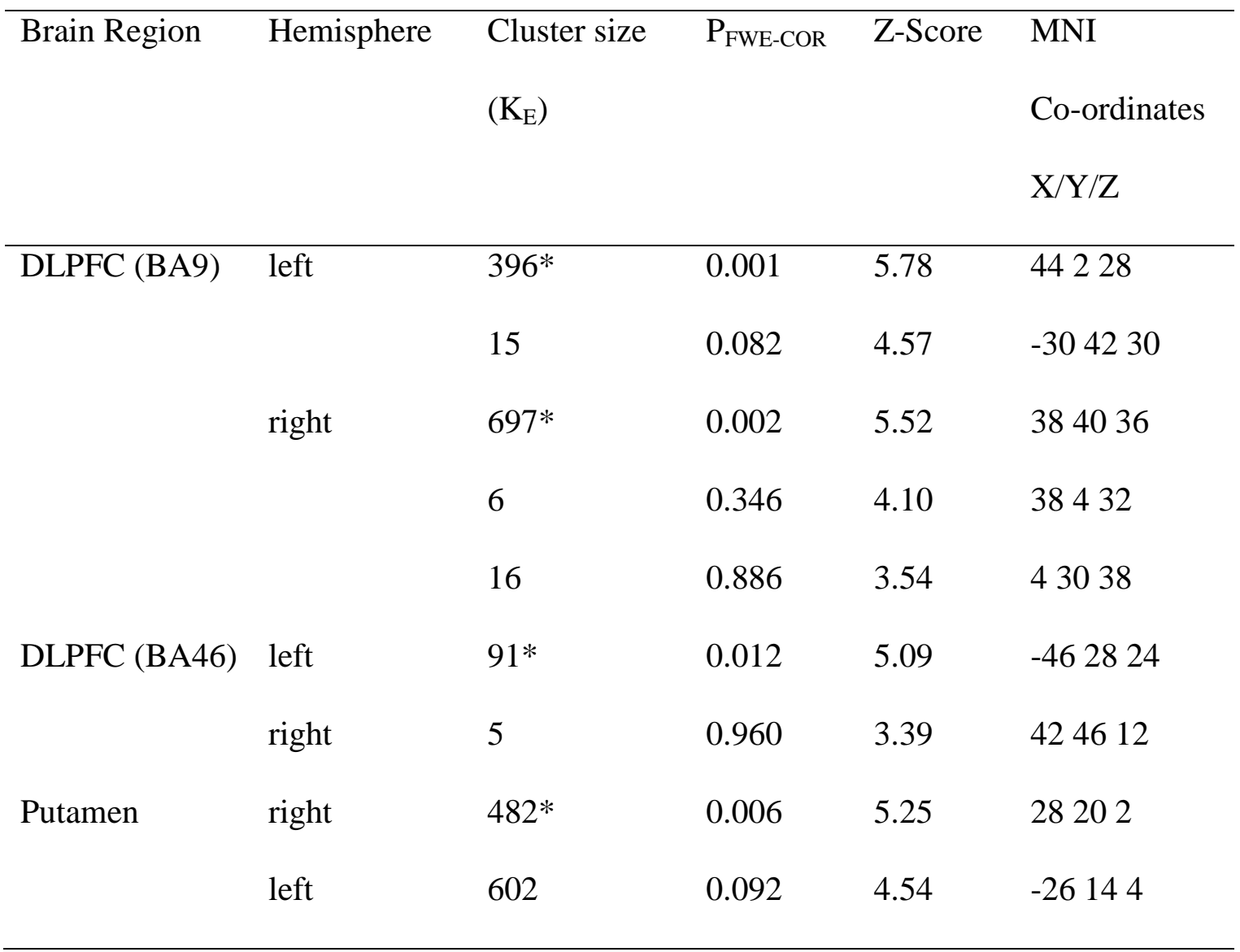


Table 4: Control group activation for 2-back versus rest, with ROI mask. Uncorrected threshold $\mathrm{p}<0.001$, cluster extent level $=5$ voxels.

\begin{tabular}{|c|c|c|c|c|c|}
\hline Brain Region & Hemisphere & $\begin{array}{l}\text { Cluster size } \\
\left(\mathrm{K}_{\mathrm{E}}\right)\end{array}$ & $\mathrm{P}_{\text {FWE-COR }}$ & Z-Score & $\begin{array}{l}\text { MNI } \\
\text { Co-ordinates } \\
\mathrm{X} / \mathrm{Y} / \mathrm{Z}\end{array}$ \\
\hline \multirow[t]{6}{*}{ DLPFC (BA9) } & left & $248 *$ & 0.001 & 5.55 & -40228 \\
\hline & & 12 & 0.072 & 4.59 & -304230 \\
\hline & & 48 & 0.349 & 4.07 & -422434 \\
\hline & right & $683^{*}$ & 0.004 & 5.33 & 442436 \\
\hline & & 6 & 0.266 & 4.18 & 38432 \\
\hline & & 8 & 0.447 & 3.97 & $46-226$ \\
\hline DLPFC (BA46) & left & 58 & 0.073 & 4.59 & -462824 \\
\hline Putamen & right & $174^{*}$ & 0.002 & 5.43 & 28202 \\
\hline \multirow[t]{2}{*}{ Caudate } & right & 218 & 0.147 & 4.37 & 14012 \\
\hline & left & 340 & 0.338 & 4.09 & $-16-216$ \\
\hline
\end{tabular}


Table 5: Control group activation for 3-back versus rest, with ROI mask. Uncorrected threshold $\mathrm{p}<0.001$, cluster extent level $=5$ voxels.

\begin{tabular}{|c|c|c|c|c|c|}
\hline Brain Region & Hemisphere & $\begin{array}{l}\text { Cluster size } \\
\left(\mathrm{K}_{\mathrm{E}}\right)\end{array}$ & $\mathrm{P}_{\mathrm{FWE}-\mathrm{COR}}$ & Z-Score & $\begin{array}{l}\text { MNI } \\
\text { Co-ordinates } \\
\mathrm{X} / \mathrm{Y} / \mathrm{Z}\end{array}$ \\
\hline \multirow[t]{2}{*}{ DLPFC (BA46) } & left & $429 *$ & 0.001 & 5.72 & -462028 \\
\hline & & $100^{*}$ & 0.009 & 5.15 & -462824 \\
\hline \multirow[t]{2}{*}{ Putamen } & right & $379 *$ & 0.001 & 5.61 & 28202 \\
\hline & left & $521 *$ & 0.019 & 4.96 & -26144 \\
\hline \multirow[t]{5}{*}{ DLPFC (BA9) } & right & $726^{*}$ & 0.001 & 5.59 & 423034 \\
\hline & & 6 & 0.212 & 4.28 & 38430 \\
\hline & & 24 & 0.585 & 3.86 & 43036 \\
\hline & left & 22 & 0.157 & 4.37 & -62836 \\
\hline & & 13 & 0.366 & 4.08 & -304230 \\
\hline Anterior & right & 65 & 0.569 & 3.88 & 82628 \\
\hline Cingulate & & & & & \\
\hline
\end{tabular}


Table 6: Colour and Word conditions versus rest for the control data versus the patient data, with ROI analysis. Uncorrected threshold $\mathrm{p}<0.001$, cluster extent level $=5$ voxels.

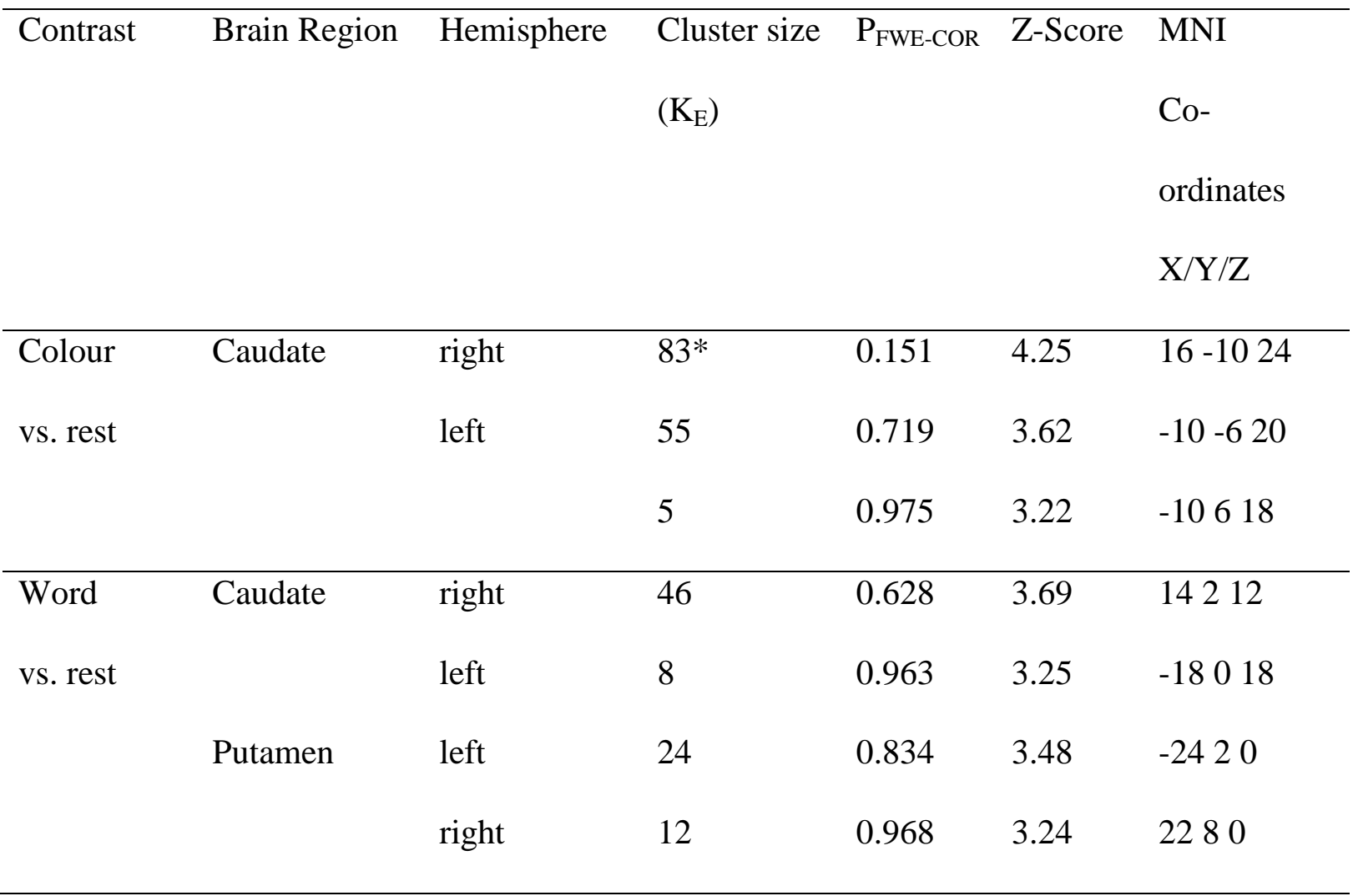


Table 7: 2-back and 3-back conditions versus rest for the control data versus the patient data, with ROI analysis. Uncorrected threshold $\mathrm{p}<0.001$, cluster extent level $=5$ voxels.

\begin{tabular}{|c|c|c|c|c|c|c|}
\hline Contrast & Brain Region & Hemisphere & $\begin{array}{l}\text { Cluster size } \\
\left(\mathrm{K}_{\mathrm{E}}\right)\end{array}$ & $\mathrm{P}_{\text {FWE-COR }}$ & Z-Score & $\begin{array}{l}\text { MNI } \\
\text { Co- } \\
\text { ordinates } \\
\mathrm{X} / \mathrm{Y} / \mathrm{Z}\end{array}$ \\
\hline 2-back & Caudate & right & 117 & 0.484 & 3.83 & $16-418$ \\
\hline vs. rest & & left & 51 & 0.891 & 3.41 & $-14-420$ \\
\hline 3-back & Caudate & left & 6 & 0.963 & 3.22 & -12818 \\
\hline
\end{tabular}




\section{Figure legends}

Figure 1: An example of a 2-back word condition

Figure 2a: RT in ms split for the factors GROUP x INSTRUCTION

Figure 2b: RT in ms split for the factors GROUP $x$ LOAD

Figure 3a: Accuracy (min. 0.0 - max. 1.0) split for the factors GROUP x INSTRUCTION

Figure 3b: Accuracy (min. 0.0 - max. 1.0) split for the factors GROUP x LOAD

Figure 4a (top) and b (bottom): Activation for controls vs. patients for colour (a) and cord (b) vs. rest

Figure 5a (top) and b (bottom): Activation for controls vs. patients for 2-back (a) and 3-back (b) vs. rest. 